\title{
Comparative Study between Shunt Insertion and Microscopic Fenestration for Management of Arachnoid Cyst of the Brain
}

W.A.Sharshira, M.A.Elawady, M.E.El Hawary and E.F.Ibrahim

Neurosurgery, Dept., Faculty of Medicine, Benha Univ., Benha, Egypt

E-mail: eeddelnagar2@gmail.com

\begin{abstract}
Background: Arachnoid cysts are benign, extra axial, cystic lesions, filled with cerebrospinal fluid, formed due tocongenital splitting of thearachnoid layer. In the relatively uncommon event of these cysts becoming symptomatic, clinical manifestations are usually related to mass effect on adjacent structures including ventricular obstruction and subsequent hydrocephalus. With modern treatment techniques, debate continues regarding which surgical treatment is most effective. Objectives: The aim of this work is to find which one of surgical treatment is more effective for arachnoid cyst of the brain, shunt or microscopic fenestration surgery. Patients and methods: This cohort study was conducted on twenty patients presented with symptomatic cranial arachnoid cyst managed in the Department of Neurosurgery, Banha University Hospital and in Al-Ahrar Teaching Hospital. All patients were operated by shunt insertion in 10 patients and microscopic fenestration into basal cistern with excision of the cyst wall in the other 10 patients. Results: The study included thirteen males and seven females with male predominance in $65 \%$ of the cases. The age of the patients in this study ranged from one month to 15 years. There are statistically non-significant differences between the studied groups regarding age, gender, operative time, follow-up time, stay in ICU or ward, total hospital stay, postoperative complications, outcome or need for reoperation. Conclusion: There is no actual difference between microscopic fenstration of arachnoid cyst and cystoperitoneal shunt.
\end{abstract}

Keywords: arachnoid cysts of brain, shunt insertion, microscopic fenestration.

\section{Introduction}

Arachnoid cysts are cerebrospinal fluid covered by arachnoidal cells and collagen that may develop between the surface of the brain and the cranial base or on the arachnoid membrane, one of the three meningeal layers that cover the brain and the spinal cord. Primary arachnoid cysts are a congenital disorder whereas secondary arachnoid cysts are the result of head injury. Most cases of primary cysts begin during infancy; however, onset may be delayed until adolescence $^{[1]}$.

The need for treatment of arachnoid cysts is controversial and is generally reserved for cysts proven to be causing focal neurologic symptoms or signs not attributable to other causes. For this reason, a detailed history and examination along with appropriate imaging is essential in determining if the described symptoms are attributable to the cyst. It is worth mentioning that an unwanted effect of discovery of true "incidentalomas" is the causation of unnecessary concern to a patient that would otherwise likely never have been affected by the presence of an arachnoid cyst ${ }^{(2)}$.

Treatment strategies are based on two major considerations: inadequate communication between the cyst and the subarachnoid space or increased intracranial pressure despite sufficient communication. Surgical options include open-craniotomy or endoscopic cyst fenestration, cysto-peritoneal shunt insertion or marsupialization via a craniotomy. The qualities of each technique continue to be the subject of much debate due to limited understanding of the pathophysiologic mechanisms and natural history of this pathology ${ }^{[3]}$. Stratejileri et al. ${ }^{[4]}$ reported that $33 \%$ were treated by microscopic fenestration, only
$20 \%$ were treated by endoscopic fenestration, and $47 \%$ were treated by cystoperitoneal shunting.

Advances in neurosurgical techniques and endoscopy techniques continue to favor fenestration over shunt insertion. The complications of these procedures include subdural hematomas, hygromas, hydrocephalus, and more rarely intraparenchymal hemorrhage ${ }^{[5]}$.

The aim of this work is to find which one of surgical treatment options is more effective for arachnoid cyst of the brain, shunt or microscopic fenestration surgery? By comparative study of twenty cases, 10 cases were for shunt insertion and 10 cases were for microscopic fenestration a trial to find the best way to reach the best results in order to lessen the complications and avoiding shunt dependence.

\section{Patients and Methods}

This cohort study was conducted on twenty patients presented with symptomatic cranial arachnoid cyst managed in the Department of Neurosurgery, Banha University Hospital and in Al-Ahrar Teaching Hospital.

Inclusion criteria

- Patients presenting with manifestations of increased intracranial pressure.

- Medically fit patients.

- Evidence of increasing cyst size on serial imaging.

- Imaging evidence of local pressure on vital structures by Magnetic Resonance Imaging (MRI). 


\section{Exclusion criteria}

- Asymptomatic patients with incidental findings without associated symptoms and/or significant mass effect.

- Patients with history of CNS infection.

- Medically unfit patients for surgery.

Methods:

Complete history taking and general examination: Detailed history of:

- Symptoms of increase intracranial pressure.

- Symptoms of cranial nerve dysfunctions.

- Symptoms of motor system dysfunctions.

- Symptoms of sensory system dysfunctions.

- Symptoms of cerebellar dysfunctions.

- Symptoms of spine dysfunctions.

- Symptoms of higher brain functions disturbance.

- Symptoms suggesting epilepsy.

- Symptoms of hypothalamic or pituitary dysfunctions.

- Symptoms of autonomic system dysfunctions.

Neurological examination:

- Higher functions.

- Cranial nerves.

- Sensory system.

- Motor system.

- Reflexes.

- Cerebellum.

- Spine examination.

- Special tests.

Investigations:

Computerized tomography (CT) and Magnetic Resonance Imaging (MRI) was done preoperatively and during $1^{\text {st }}$ week or as emergency in surgically managed patients.

\section{Surgical procedures:}

After selection of patients, the surgical procedure encountered in our study was discussed with patient's parents according to the surgical equipments available in our department with full illustration for advantages and disadvantages and possible complications and then final decision was made for each patient.

After written consent from patient's relatives, all patients were operated by shunt insertion in 10 patients and microscopic fenestration into basal cistern with excision of the cyst wall in the other 10 patients.

\section{Follow up:}

Follow-up of patients was done at three, six and twelve month's post-operatively through:

Clinical follow-up: Vital signs, consciousness level, postoperative medications (antibiotics, antiepileptic if required and pain killers) and daily dressing.

Radiological follow-up: Follow up CT brain was done after 3 months and at the end of the follow up period.

\section{Postoperative follow up:}

Postoperative outcome has been defined both clinically and radiologically. To define clinical outcome, we considered symptoms of increased intracranial pressure, focal neurological symptoms and signs while symptoms of psychomotor retardation were not considered because they are not related to the changes of the size of the cyst. Clinical outcome was defined as improved, unchanged and resolved.

Radiological outcome was defined according to size of cyst on three months follow up MRI. Cyst was classified as disappeared, reduced in size or unchanged. Recorded postoperative complications such as infection, hemorrhage, subdural fluid collections and CSF leak were considered.

Statistical analysis:

Data were entered checked and analyzed using EpiInfo version 6 and SPP for Windows version 8.

Data were summarized using the arithmetic mean, standard deviation, median, student $t$ test and chisquared test.

For all above mentioned statistical tests done, the threshold of significance is fixed at 5\% level (p-value).

\section{The results were considered:}

- Significant when the probability of error is less than $5 \%(\mathrm{p}<0.05)$.

- Non-significant when the probability of error is more than $5 \%(\mathrm{p}>0.05)$.

- Highly significant when the probability of error is less than $0.1 \%(\mathrm{p}<0.001)$.

The smaller the $\mathrm{p}$-value obtained, the more significant are the results.

\section{Results}

There is statistically non-significant difference between the studied groups regarding age or gender table (1).

There is statistically non-significant difference between the studied groups regarding operative time table (2).

There is statistically non-significant difference between the studied groups regarding follow up time table (3).

There is statistically non-significant difference between the studied groups regarding stay in ICU, ward or total hospital stay table (4).

There is statistically non-significant difference between the studied groups regarding postoperative complications table (5).

There is statistically non-significant difference between the studied groups regarding outcome table (6).

There is statistically non-significant difference between the studied groups regarding need for reoperation table (7). 
Table (1) Comparison between the studied groups regarding demographic data.

\begin{tabular}{|c|c|c|c|c|}
\hline \multirow[b]{2}{*}{ Parameters } & \multicolumn{2}{|c|}{ Groups } & \multicolumn{2}{|c|}{ Test } \\
\hline & $\begin{array}{l}\text { Cysto-peritoneal shunt group } \\
\mathrm{N}=10(\%)\end{array}$ & $\begin{array}{l}\text { Microscopic fenestration group } \\
\qquad \mathrm{N}=10(\%)\end{array}$ & $\mathrm{Z} / \chi^{2}$ & $\mathbf{p}$ \\
\hline \multicolumn{5}{|l|}{ Age (month): } \\
\hline Median & 75 & 58 & - & \multirow{2}{*}{0.544} \\
\hline Range & $5-180$ & $1-175$ & 0.606 & \\
\hline \multicolumn{5}{|l|}{ Gender: } \\
\hline Male & $7(70)$ & $6(60)$ & \multirow{2}{*}{ Fisher } & \multirow{2}{*}{$>0.999$} \\
\hline Female & $3(30)$ & $4(40)$ & & \\
\hline
\end{tabular}

Z Mann Whitney test $\chi^{2}$ Chi square test

Table (2) Comparison between the studied groups regarding operative time.

\begin{tabular}{|c|c|c|c|c|}
\hline \multirow[b]{2}{*}{ Parameters } & \multicolumn{2}{|c|}{ Groups } & \multicolumn{2}{|c|}{ Test } \\
\hline & $\begin{array}{l}\text { Cysto-peritoneal shunt group } \\
\qquad \mathrm{N}=10\end{array}$ & $\begin{array}{l}\text { Microscopic fenestration group } \\
\qquad \mathrm{N}=10\end{array}$ & $\mathbf{t}$ & $\mathbf{p}$ \\
\hline Operative time & & & & \\
\hline $\begin{array}{l}\text { Mean } \pm \text { SD } \\
\text { Range }\end{array}$ & $\begin{array}{c}102.5 \pm 9.5 \\
5-180 \\
\end{array}$ & $\begin{array}{c}108.8 \pm 8.68 \\
1-175\end{array}$ & -1.548 & 0.139 \\
\hline
\end{tabular}

$\mathrm{t}$ independent sample $\mathrm{t}$ test

Table (3) Comparison between the studied groups regarding follow up time.

\begin{tabular}{lcccc}
\hline & \multicolumn{2}{c}{ Groups } & \multicolumn{2}{c}{ Test } \\
Parameters & $\begin{array}{c}\text { Cysto-peritoneal shunt group } \\
\mathbf{N = 1 0}\end{array}$ & $\begin{array}{c}\text { Microscopic fenestration group } \\
\mathbf{N = 1 0}\end{array}$ & $\mathrm{t}$ & $\mathrm{p}$ \\
\hline $\begin{array}{l}\text { Follow up time } \\
\text { Mean } \pm \text { SD }\end{array}$ & $16.5 \pm 3.41$ & $14.9 \pm 2.6$ & & \\
Range & $12-21$ & $12-20$ & 1.18 & 0.253 \\
\hline
\end{tabular}

$t$ independent sample $t$ test

Table (4) Comparison between the studied groups regarding hospital stay.

\begin{tabular}{|c|c|c|c|c|}
\hline \multirow[b]{2}{*}{ Parameters } & \multicolumn{2}{|c|}{ Groups } & \multicolumn{2}{|c|}{ Test } \\
\hline & $\begin{array}{l}\text { Cysto-peritoneal shunt group } \\
\qquad \mathrm{N}=10\end{array}$ & $\begin{array}{l}\text { Microscopic fenestration group } \\
\qquad N=10\end{array}$ & $\mathbf{Z}$ & $\mathbf{p}$ \\
\hline \multicolumn{5}{|l|}{ ICU } \\
\hline Mean $\pm \mathrm{SD}$ & 1 & 0.5 & \multirow{2}{*}{-1.057} & \multirow{2}{*}{0.291} \\
\hline Range & $0-3$ & $0-2$ & & \\
\hline \multicolumn{5}{|l|}{ Ward } \\
\hline Mean \pm SD & 1.5 & 1 & \multirow{2}{*}{-0.82} & \multirow{2}{*}{0.412} \\
\hline Range & $1-3$ & $1-3$ & & \\
\hline \multicolumn{5}{|l|}{ Hospital } \\
\hline Mean $\pm \mathrm{SD}$ & 3 & 2.5 & \multirow{2}{*}{-1.087} & \multirow{2}{*}{0.277} \\
\hline Range & $1-5$ & $1-5$ & & \\
\hline
\end{tabular}

\section{Z Mann Whitney test}

Table (5) Comparison of the studied groups according to complications.

\begin{tabular}{lcccc}
\hline Parameters & \multicolumn{2}{c}{ Groups } & \multicolumn{2}{c}{ Test } \\
& $\begin{array}{c}\text { Cysto-peritoneal shunt group } \\
\text { N=10 (\%) }\end{array}$ & $\begin{array}{c}\text { Microscopic fenestration group } \\
\mathbf{N = 1 0}(\%)\end{array}$ & $\chi^{\mathbf{2}}$ & $\mathbf{p}$ \\
\hline Complications & & & & \\
No & $5(50)$ & $8(80)$ & Fisher & $>0.999$ \\
Subdural hygroma & $3(30)$ & $2(20)$ & 0.8 & 0.371 \\
Hydrocephalus & $1(10)$ & $0(0)$ & Fisher & $>0.999$ \\
Massive subdural hematoma & $1(10)$ & $0(0)$ & Fisher & $>0.999$ \\
\hline
\end{tabular}

$\chi^{2}$ Chi square test 
Table (6) Comparison of the studied groups according to outcome.

\begin{tabular}{lcccc}
\hline Parameters & \multicolumn{2}{c}{ Groups } & \multicolumn{2}{c}{ Test } \\
& $\begin{array}{c}\text { Cysto-peritoneal shunt group } \\
\mathbf{N = 1 0}(\boldsymbol{\%})\end{array}$ & $\begin{array}{c}\text { Microscopic fenestration group } \\
\mathbf{N = 1 0}(\boldsymbol{\%})\end{array}$ & $\chi^{\mathbf{2}}$ & $\mathbf{p}$ \\
\hline Outcome & $1(10)$ & $0(0)$ & & \\
Unchanged & $4(40)$ & $5(50)$ & 0.137 & 0.712 \\
Improved & $5(50)$ & $5(50)$ & & \\
Resolved & & &
\end{tabular}

\section{$\chi^{2}$ Chi square test}

Table (7) Comparison between the studied groups regarding reoperation.

\begin{tabular}{lcccc}
\hline \multirow{2}{*}{ Parameters } & \multicolumn{2}{c}{ Groups } & \multicolumn{2}{c}{ Test } \\
& $\begin{array}{c}\text { Cysto-peritoneal shunt group } \\
\mathbf{N = 1 0}(\%)\end{array}$ & $\begin{array}{c}\text { Microscopic fenestration group } \\
\mathbf{N = 1 0}(\%)\end{array}$ & $\chi^{\mathbf{2}}$ & $\mathbf{p}$ \\
\hline Reoperation: & $7(70)$ & $8(80)$ & & \\
No & $3(30)$ & $2(20)$ & Fisher & $>0.999$ \\
Yes & & & & \\
\hline
\end{tabular}

$\chi^{2}$ Chi square test

Case No. (1)

An 8-year-old boy presented with a history of intermittent headache and nausea. One week prior to his presentation he had slipped while walking. There was no history of loss of consciousness at the time of the injury. His neurological examination was unremarkable and there was no focal neurological abnormality, cranial nerve deficit, or papilledema. He had no significant past medical history. CT of the brain showed a left middle cranial fossa arachnoid cyst with an associated left-sided subdural hygroma, causing mass effect with ipsilateral ventricular compression and effacement of the convexity sulcal spaces. The patient underwent surgery we put cysto peritonail shunt. His symptoms resolved immediately and he made an uneventful recovery. Figure $(1,2)$

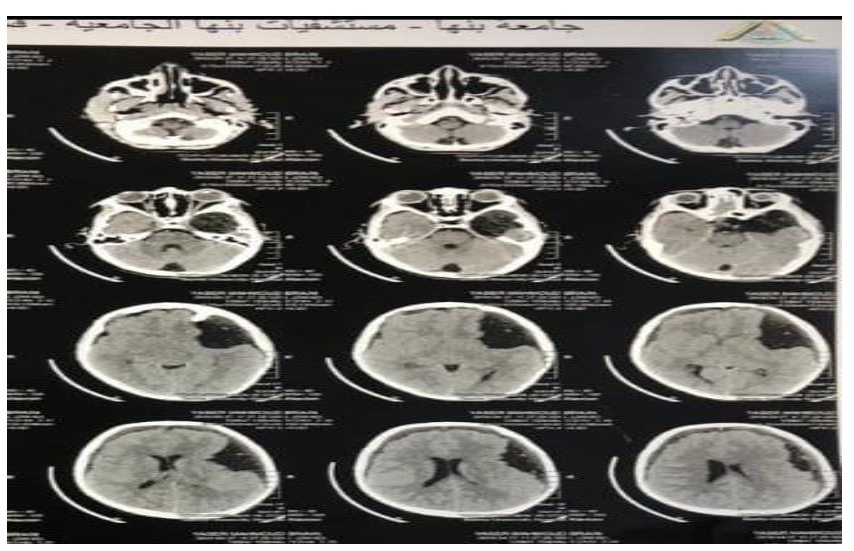

Fig. (1) CT brain at different levels show a left middle cranial fossa arachnoid cyst with an associated subdural hygroma.

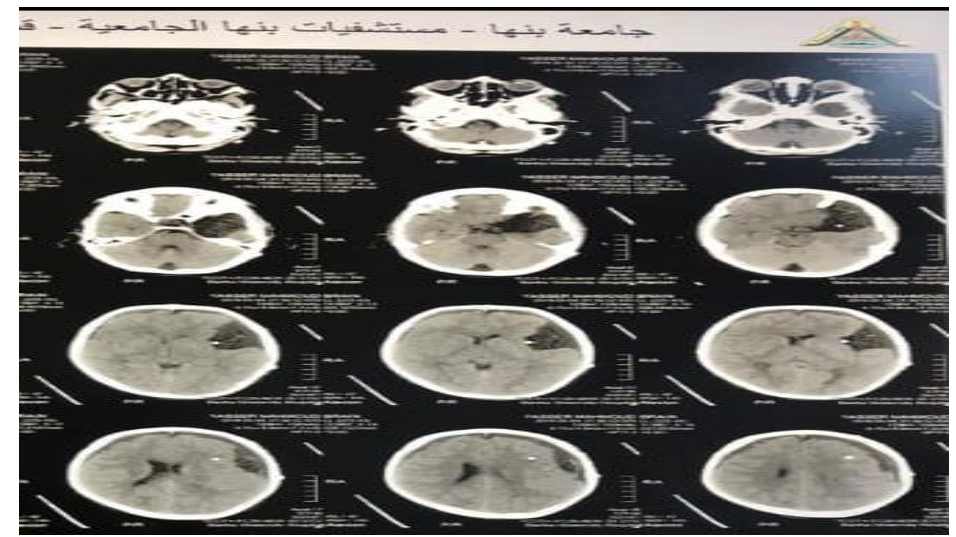

Fig. (2) CT images show a hypointense arachnoid cyst and an associated subdural hygroma (post oprative) 


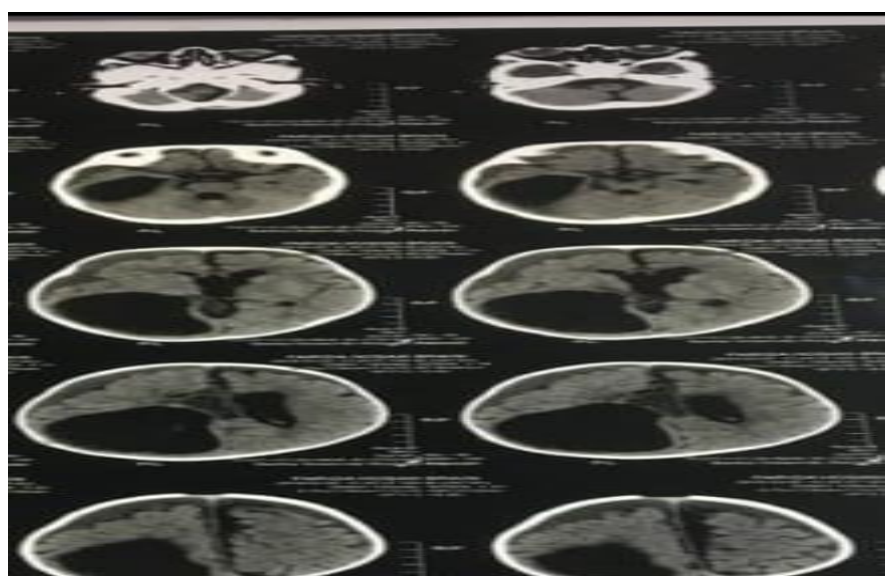

Fig. (3) Preoperative microscopic fentration.

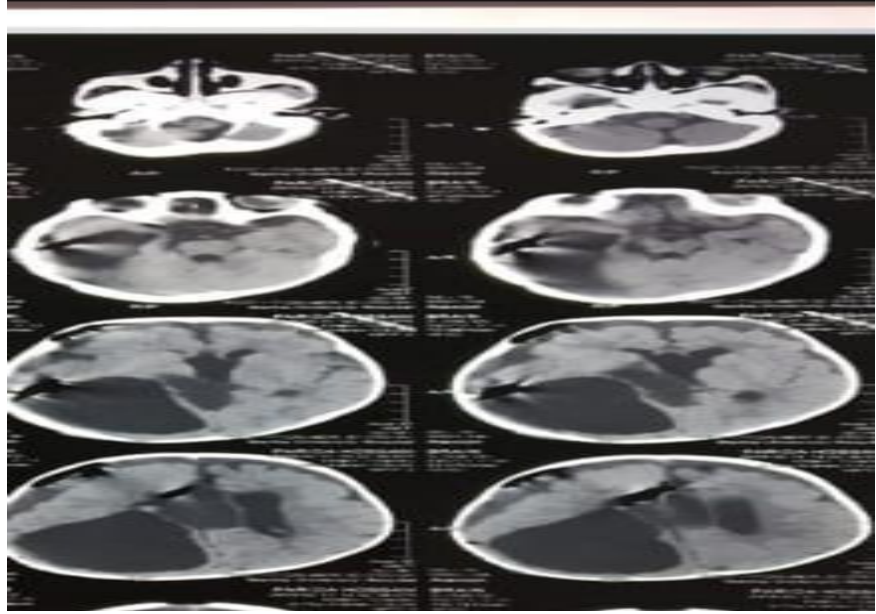

Fig. (4) Postoperative microscopic fenestration.

Case No. (2)

A 5-year- old girl presented with a history of intermittent headache and nausea. One week prior to her presentations she had slipped while walking. There was a history of loss of consciousness at the time of the injury. Her neurological examination was unremarkable and there was focal neurological abnormality in the form of fits, cranial nerve deficit in the form of sixth nerve palsy, and papilledema. She had significant past medical history. MRI of the brain showed a right parito occipital fossa arachnoid cyst, causing mass effect with ipsilateral ventricular compression and effacement of the convexity sulcal spaces. The patient underwent surgery, and cyst fenestration and. His symptoms resolved immediately and he made an uneventful recovery. Figure $(3,4)$

\section{Discussion}

Arachnoid cysts are common among the general population and with increased development of neuroradiology, arachnoid cysts are being incidentally diagnosed more often. They are frequently encountered CSF collections in the central nervous system, with preponderance in the middle cranial fossa [5].
The most common locations for intracranial arachnoid cysts are the middle fossa (near the temporal lobe), the suprasellar region (near the third ventricle) and the posterior fossa, which contains the cerebellum, pons, and medulla oblongata. The presenting symptoms and signs are closely related to the expansion of arachnoid. Some cysts remain asymptomatic while others may expand and cause symptomatic compression on surrounding structures [6].

The etiology of arachnoid cysts has been a controversial subject and still remains unclear. Arachnoid cysts could be congenital cysts (also called 'true' arachnoid cysts and is the most common type) or secondary arachnoid cysts that result from CSF sequestration due to inflammatory or following traumatic processes, hemorrhage, chemical irritation, and tumors [7].

Arachnoid cysts that produce symptoms should be treated. Surgical options include open-craniotomy or endoscopic cyst fenestration, cysto-peritoneal shunt insertion or marsupialization via a craniotomy. Advances in neurosurgical techniques and endoscopy techniques continue to favor fenestration over shunt insertion. The complications of these procedures include subdural hematomas, hygromas, 
hydrocephalus, and more rarely intraparenchymal hemorrhage [5].

The aim of this work is to find which one of surgical treatment is more effective for arachnoid cyst of the brain, shunt or microscopic fenestration surgery. This cohort study was conducted on twenty patients presented with symptomatic cranial arachnoid cyst managed in the Department of Neurosurgery, Banha University Hospital and in Al-Ahrar Teaching Hospital.

All patients were operated by shunt insertion in 10 patients and microscopic fenestration into basal cistern with excision of the cyst wall in the other 10 patients. The study included thirteen males and seven females with male predominance in $65 \%$ of the cases. The age of the patients in this study ranged from one month to 15 years. The median age was 75 months in shunt insertion group and 58 months in microscopic fenestration group. Statistically, there are nonsignificant differences between the studied groups regarding age and gender, and this was matching with the study done by Di Rocco et al.[8] as sex distribution was exactly $70 \%$ boys and $30 \%$ girls and slightly different from another study in which the mean age was 4.3 years $(\mathbf{9})$.

Abd El-Kader and Al-Emam [10] study included fourteen males and six females (2.3:1) with male predominance in $70 \%$ of the cases. The age of the patients in this study ranged from 6 months to 10 years. The mean age was 5.3 years.

El-Sherbiny et al. [11] evaluated the cases of intracranial arachnoid cysts clinically and radiologically and the possibility of surgery. The study included 22 managed cases of arachnoid cyst (15 Medically managed and 7 Surgically managed). Patients in the surgically managed group were subdivided to 3 groups according to type of surgery: Group A was treated by cysto-peritoneal shunt and contained 2 cases $(28.6 \%)$, group B was treated by open craniotomy and microscopic fenestration and contained 2 cases $(28.6 \%)$, and group $\mathrm{C}$ was treated by endoscopic fenestration and contained 3 cases $(42.9 \%)$. The mean age of the totally managed cases was $12.1 \pm 9.3$ years, for the medically managed group was $13.8 \pm 9.4$, and for the surgically managed cases was $8.4 \pm 8.3$. There was no statistical significant difference in age between the medical management group and surgical management group. The study includes $63.6 \%$ male cases and $36.4 \%$ female cases.

In our study, the most common presentation was vomiting which was observed in ten patients $(50 \%)$ followed by headache which was observed in seven patients $(35 \%)$. Seizures were observed in two patients $(10 \%)$. Nausea was in one patient $(5 \%)$, weakness in one patient $(5 \%)$ and also cerebellar signs were in one patient (5\%). Statistically, there is non-significant difference between the studied groups regarding clinical presentation.

In the study done by Gangemi et al. [12], $18 \%$ of patients had seizures and $56 \%$ of patients were complaining of headache, and in another study, headache was the most common symptom in (32\%) patients [13].

In our study, the most common complications were subdural hygroma in five patients $(25 \%)$. Hydrocephalus was only in one patient (5\%) and massive subdural hematoma was only in one patient $(5 \%)$. Statistically, there is non-significant difference between the studied groups regarding postoperative complications.

In another study, endoscopic treatment of arachnoid cysts resulted in subdural hematomas in 5\% of cases [14]. Abd El-Kader and Al-Emam [10] found that the most common complications were infection in three patients $(15 \%)$ and transient cerebrospinal fluid (CSF) leakage in only one patient $(5 \%)$.

El-Sherbiny et al. [11] found that most surgically managed cases was complicated (57.2\%) and (42.8\%) showed no complications, that most common complication was hydrocephalus in $3(42.9 \%)$ patients, followed by bleeding and subdural collection in $2(28.6 \%)$ patients for each one.

This difference may be due to: the use of more advanced instruments (endoscopes and microscopes), less surgeon experience, limited sample size, and short period of our study.

Regarding the outcome of patients in our study, unchanged outcome was observed in one patient $(5 \%)$, improved outcome in nine patients $(45 \%)$, while resolved outcome was observed in ten patients $(50 \%)$. Statistically, there is non-significant difference between the studied groups regarding outcome.

Helland et al. [15] had found that symptoms had disappeared completely in $47 \%$ of patients. On another side, Gangemi et al. [12] reported that about $93 \%$ of patient treated with cystoperitoneal shunt showed good clinical outcome. Wang et al. [16] showed that cyst reduction was achieved in $77.8 \%$ of patients at the last follow-up after cystoperitoneal shunting.

Hall et al. [17] showed improvement or resolution of symptoms was seen in $88 \%$ of patients treated endoscopic ally, $88 \%$ of patients treated micro surgically, and $100 \%$ of patients treated by shunting. El-Sherbiny et al. [11] observed patients with satisfactory clinical outcome were observed in most of the total managed cases in $16(72.7 \%)$ patients. There was a statistical significant difference in clinical outcome between the medical management group and the surgical management group as almost medically managed patients $13(86.7 \%)$ were improved clinically. Non improved medically managed patients (2 patients) refused any surgical intervention and asked to complete their symptomatic treatment and to follow up. Patients were categorized into one of three possible radiological outcome groups (improved, no change and worsen). Improved radiological outcome was observed in $3(42.9 \%)$ of surgically managed patients. All medically managed patients 15 (100.0\%) did not change radio logically. 
In our study, fifteen patients $(75 \%)$ did not need another surgery, while only five patients $(25 \%)$ need another surgery, with statistically non-significant difference between shunt insertion group and microscopic fenestration group regarding need for reoperation. This was slightly different from the results of Yadav et al. [18] as 38.8\% required a second intervention to resolve the clinical condition.

Selection of the surgical modality depends on proper evaluation, surgeon experience, socioeconomic level of the patient and his consent, the surgical equipments available in our department. We believe that open and permanent fenestration achieved by open surgery and excision of the cyst wall will reduce the ability of secretion of cyst fluid and thus will reduce the possibility of recurrence. Because of the previously mentioned reasons, we chose microscopic fenestration into the basal cisterns and excision of the wall and this correlated with Serdar [19] who treated twenty five cases by microscopic fenestration with good outcome.

\section{Conclusion}

Selection of the surgical modality depends on proper evaluation, cyst location, size, associated complications, surgeon experience and patient consent. Management of intracranial arachnoid cyst remains controversial and most of the patients managed conservatively but we believe that once surgical option has been chosen, it should be performed as early as possible to avoid skull-brain mismatch and prevent pressure from the cyst on the underlying developing brain. Selection of the surgical modality depends on proper evaluation, surgeon experience, socioeconomic level of the patient and his consent.

In conclusion, there is no actual difference between microscopic fenstration of arachnoid cyst and cystoperitoneal shunt.

\section{References}

[1] S.Ariai, A.Koerbel, A.Bornemann, Cerebellopontine angle arachnoid cyst harbouring ectopic neuroglia. Pediatr Neurosurg.vol.41 (4),pp.220-3,2005.

[2] T.Westermaier, T.Schweitzer, RI.Ernestus, Arachnoid cysts. Adv Exp Med Biol.vol.724,pp.37-50,2012.

[3] A.Bahl, DJ.Connolly, S.Sinha, Rapid brain shift, remote site hemorrhage, and a spinal hematoma after craniotomy for a large arachnoid cyst. J Pediatr Neurosci.vol.7(2),pp.106-8,2012.

[4] İ.A.K.C.Y.Stratejileri, B.Merkezin, and O.Tecrübesi, Surgical management strategies of intracranial arachnoid cysts: a single institution experience of 75 cases. Turkish Neurosurgery.vol.22(5),pp.591-598,2012.

[5] T.Auschwitz, M.DeCuypere, N.Khan, Hemorrhagic infarction following open fenestration of a large intracranial arachnoid cyst in a pediatric patient. J Neurosurg Pediatr.vol.15(2),pp.203-6,2015.

[6] Z.S.Ali, S.S.Lang, D.Bakar, Pediatric intracranial arachnoid cysts: comparative effectiveness of surgical treatment options. Child's Nervous System.vol.30(3),pp.461469,2014.

[7] Y.Tohma, L.Hayashi, Obstructive hydrocephalus associated with arachnoid cyst in the elderly. J Clin Neurosci .vol.11,pp.5424,2013.

[8] C.Di Rocco, Richter, Limits of endoscopic treatment of sylvian arachnoid cysts in children. Childs Nerv Syst.vol.26,pp.155-62,2011.

[9] J.Y.Lee, J.W.Kim, J.H.Phi, Enlarging arachnoid cyst: a false alarm for infants. Child's Nervous System.vol.28(8),pp.1203-1211,2012.

[10]HE.Abd El-Kader and AI.Al-Emam, The effectiveness of microsurgical marsupialization and fenestration. Egyptian Journal of Neurosurgery.vol.31(1),pp.7-12,2016.

[11] AM.El-Sherbiny, IM.Al-Aghory and OM.ElGhannam, Management of intracranial arachnoid and porencephaliccysts (conservative versus surgical). Al-Azhar Med. J. (Surgery).vol.50(1),pp.25-34,2021.

[12] M.Gangemi, V.Seneca, G.Colella, Endoscopy versus microsurgical cyst excision and shunting for treating intracranial arachnoid cysts. Journal of Neurosurgery: Pediatrics.vol.8(2),pp.158$164,2011$.

[13] M.Sharma, R.S.Mittal, R.Bansal, Intracranial arachnoid cyst: An institutional experience. Romanian Neurosurgery,pp.136-142,2016.

[14]R.D.Johnson, S.Chapman, and S.Bojanic, Endoscopic fenestration of middle cranial fossa arachnoid cysts: Does size matter? Journal of Clinical Neuroscience.vol.18(5),pp.607$612,2011$.

[15]CA.Helland, M.Lund-Johansen, K.Wester, Location, sidedness, and sex distribution of intracranial arachnoid cysts in a populationbased sample. J Neurosurg, 2010.

[16] Y.Wang, F.Wang, M.Yu, Clinical and radiological outcomes of surgical treatment for symptomatic arachnoid cysts in adults. Journal of Clinical Neuroscience.vol.22(9),pp.1456$1461,2015$.

[17] S.Hall, A.Smedley, O.Sparrow, Natural History of Intracranial Arachnoid Cysts. World Neurosurg.vol.126,pp.e1315-e1320,2019.

[18] YR.Yadav, V.Parihar, S.Pande, Endoscopic third ventriculostomy. J Neurosci Rural Pract.vol.3, pp.163-173,2012.

[19] K.Serdar, Surgical management strategies of intracranial arachnoid cysts: a single institution experience of 75 cases. Turk Neurosurg.vol.22,pp.591-98,2012. 